\section{BMJ Paediatrics Open}

\title{
Scoping exercise to develop a storybook to support children's education during the COVID-19 pandemic
}

Rowshonara Syeda, ${ }^{1}$ Magdalena Hann (D , ${ }^{1}$ Rosalie Allison (D) , ${ }^{1}$ Alicia Demirjian ${ }^{1,2}$

To cite: Syeda R, Hann M, Allison R, et al. Scoping exercise to develop a storybook to support children's education during the COVID-19 pandemic. BMJ Paediatrics Open 2021;5:e000926. doi:10.1136/ bmjpo-2020-000926

- Additional material is published online only. To view, please visit the journal online (http://dx.doi.org/10.1136/ bmjpo-2020-000926).

Received 9 November 2020 Revised 5 February 2021 Accepted 7 February 2021
Check for updates

\section{(C) Author(s) (or their} employer(s)) 2021. Re-use permitted under CC BY-NC. No commercial re-use. See rights and permissions. Published by BMJ.

${ }^{1}$ Primary Care and Interventions Unit, Public Health England, Gloucester, UK

${ }^{2}$ Children's \& Adolescent Services, Evelina London Children's Hospital, London, UK

\section{Correspondence to} Dr Rosalie Allison; Rosie. Allison@phe.gov.uk

\section{ABSTRACT}

Objective In June 2020, as COVID-19 lockdown measures were eased in the UK, this scoping exercise aimed to rapidly identify topics to cover within a children's online storybook 'My Back to School Bubble', designed to support the return to school.

Methods An email invitation was sent to 71 known contacts within networks across Public Health England, local authorities, health protection teams and contacts within the Department for Education. Following online publication of 'My Back to School Bubble', users were asked to provide informal feedback via an online survey to ask about their impressions of the story.

Results Findings from the 31 responses highlighted that children are likely to hold differing feelings regarding COVID-19, depending on their own temperament and lockdown experiences, including changes in relationships with family and friends. Following the launch of 'My Back to School Bubble' e-storybook, 21 users provided feedback via survey. Fourteen respondents $(67 \%)$ indicated that the storybook was a useful tool for providing support to children, and twelve (57\%) reported that the resource helped children understand their own feelings.

Recommendations Clear, accurate information about the new school environment should be provided in the context of COVID-19. It is especially important to support children with special educational needs and disabilities, including those with autism. Encouraging children to take ownership of their health and hygiene behaviours, such as handwashing, will help to normalise this and prevent the spread of infection. Lessons learnt from the development of 'My Back to School Bubble' online storybook suggest the clarity of imagery could be improved to better support children with autism. Future work should focus on longitudinal and qualitative research. This should include the long-term effects of the pandemic on children's development and education, effects on mental health and resilience, peer socialisation, and ability to cope with lifechanging events.

\section{BACKGROUND}

Since January 2020, a vast number of resources ${ }^{1-6}$ have been created to educate children and young people about COVID19. These explore what COVID-19 is, how it spreads, and how to change behaviours to reduce the risk of infection and transmission of the SARS-CoV-2. ${ }^{7}$ In June 2020, as primary

\section{What is known about the subject?}

- Many resources were developed for children during the COVID-19 pandemic including several stories, all examples of these were designed to support 'stay at home' measures.

- Schools in the UK started to return from June 2020, at this time no resources aimed at children existed to support this.

- 'Social stories' provide information about what to expect in certain situations; they have successfully supported autistic children and could help children understand new guidance.

\section{What this study adds?}

This scoping exercise highlights that parents/carers and teachers should provide up to date information regarding school changes and encourage good hygiene behaviours.

- Providing information about hygiene must be in combination with reassurance if children forget the rules, to combat anxiety.

- When producing new resources, images should be inclusive and clear to all.Feedback indicates special educational needs and disabilities students may favour photographs, or greater clarity in illustrations.

schools prepared to welcome back the first groups of children following lockdown restrictions, a gap in age-appropriate resources to support these children was identified.

The Primary Care and Interventions Unit at Public Health England (PHE) operates the educational resource e-Bug, which helps teach 4-18years old about hygiene, infections and antibiotics, with interactive, visual and age-appropriate resources. ${ }^{8}$ e-Bug is an international resource, endorsed by the National Institute of Health and Care Excellence and recommended by the Department for Education to teach hand washing and promote antimicrobial stewardship. $^{9} 10$ The e-Bug resources have been found to be successful in educating children about infection prevention and hygiene in peer-led lessons, science 
shows and classroom gaming. ${ }^{11-14}$ The e-Bug team aimed to create a storybook 'My Back to School Bubble' to host on the e-Bug website, ${ }^{8}$ to support the transition of children returning to school.

In England, the protective measures to support children returning to school, included ${ }^{10}$ :

1. Minimising contact with individuals who are unwell by ensuring that those who have COVID-19 symptoms, or who have someone in their household who does, do not attend school.

2. Cleaning hands thoroughly more often than usual.

3. Ensuring good respiratory hygiene by promoting the 'catch it, bin it, kill it' approach.

4. Introducing enhanced cleaning, including cleaning frequently touched surfaces often, using standard products such as detergents and bleach.

5. Minimising contact between individuals and maintaining social distancing wherever possible.

'Social stories' have been successfully used to encourage children with autism to communicate key messages and develop a better understanding of reallife situations, activities and events, and encourage positive responses to changes in routine. ${ }^{5}$ Although initially designed to support children with autism to stay safe and find meaning in rules and routines, similar stories can be used to reassure children of all ages and abilities to deal with life changes, including the COVID-19 pandemic.

\section{Aim}

As COVID-19 lockdown measures were eased in the UK, the aim of this scoping exercise was to rapidly collate feedback on topics for a children's storybook to support the return of primary school children to educational settings. The storybook was intended to address children's fears and anxieties, and this study aimed to illuminate practical ways to support children returning to school. These reccommendations would be suitable for school and community educators, and public health professionals, including government bodies.

\section{METHODS}

Due to time sensitivity, a convenience sample of 71 known contacts across PHE and other national networks were approached to provide feedback on developing a resource to be used imminently in a school setting.

An email invitation to contribute storybook topics was sent at the end of May 2020, following the announcement by the government of the gradual reopening of schools in June. Participating professionals were encouraged to cascade the invitation among their networks, and asked for responses the same day, so that these could be used to develop the story within the tight timeframe.

Following online publication of 'My Back to School Bubble', users were asked to provide feedback via an online survey between June and November 2020. The survey was promoted on social media, alongside the download of 'My Back to School Bubble'. Participation was encouraged with the incentive of being entered into a prize draw for a $£ 40$ high-street voucher.

The survey included a combination of 12 Likert scale and open-ended questions, which included questions on impression, content, illustration, usefulness and relevance. The survey also asked users for recommendations for improvements.

Participants (table 1) included individuals from PHE Children, Young People and Families Centre Leads, the early years settings group within PHE, Department for Education, health protection teams and local authority representatives, with several respondents additionally reporting their own views as parents/carers.

Feedback provided by return of email was thematically analysed, independently, by two researchers (RS and MH). Qualitative data analysis software, NVivo Pro V.11, was used to sort data, including analysis of codes, quotes and themes. Both researchers then discussed and agreed on the main themes to resolve any differences.

Descriptive statistics were used to analyse evaluation survey data and free text answers were analysed using

Table 1 Composition of invited participants and contributors

\begin{tabular}{lllc}
\hline Organisation & Role/network & Approached & Contributed \\
\hline Public Health & Children Young People and Families Network (multi-organisational) & 16 & 15 \\
England/local & Children and Families Centre Leads Network & 27 & 5 \\
authorities & Schools and COVID-19 South West Coordinating Group including & 15 & 4 \\
& representatives from Health Protection & & 0 \\
& Children Young Peoples and Families Team & 8 & 2 \\
& Primary Care and Interventions Unit & 2 & 0 \\
& Health and Wellbeing & 1 & 1 \\
Department for & Educational Psychologist & (Invitation cascaded) & 2 \\
Education & Pupil Mental Wellbeing & 2 & 1 \\
Other & National Children's Bureau & (Invitation cascaded) & 1 \\
Total & & (Invitation cascaded) & 1 \\
\hline
\end{tabular}


Usefulness to support children returning to school $5 \quad 8$ Relevance to my school's COVID-19 protective measures

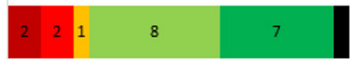

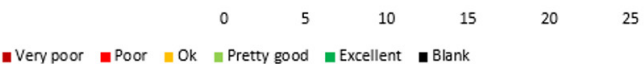

Figure 1 Users' rating of 'My back to school bubble' regarding 'usefulness to support children returning to school' and 'revelance to my school's COVID-19 protective measures'.

NVivo Pro V.11. Themes were identified by a single researcher $(\mathrm{MH})$ due to the small data set.

Due to the rapid nature of this project, teachers and students were involved through known PHE networks, rather than contacted directly. Public health professionals and members of the Department for Education provided the data, and reviewed drafts of the storybook before publication. Once finalised, the storybook was circulated via the same networks that were used for data collection.

\section{RESULTS}

In total, 31 responses to the invitation were analysed for the scoping exercise and six main themes emerged from the data (online supplemental table 2). Themes included: changes in school environment, acknowledging feelings, relationships with family, relationships with friends, language and content, and taking ownership of health and hygiene behaviours.

Changes in the classroom environment included having a different teacher, or not being in the usual classroom, and a shorter school day. Changes to classroom layout to allow more space between students, no assemblies, and physical distancing between parents, teachers and other children were also discussed. Not sharing toys or equipment and new school rules centred around good hygiene practices, including more frequent handwashing, using toilets alone and wiping all equipment after use.

It was reported that children could have several anxieties, including worries about how adults and other children will treat them and worrying about having COVID-19 and passing it on to others. There was a consensus that family time spent during lockdown, and sense of belonging should be celebrated; children may have picked up various skills, and new ways of showing affection. Various reactions, such as feeling cross and out of place will be normal during this unusual period.

Concern for others, included children who may be young carers (a young person under 18 years who helps to look after a relative with a disability, illness, mental health condition, or drug or alcohol problem). ${ }^{15}$ Some children may be concerned for vulnerable family members, andsome children will have been more isolated, especially in single-child households, therefore may exhibit greater separation anxiety from leaving their parents and family members behind.

Relationships with friends could change as children may not be in the same 'bubble' as their usual peers. Some children could be more fearful of close contact, for fear of getting the virus or spreading it, especially if they have been more isolated during the lockdown period.

The general consensus was to provide children with coherent or repetitive take home messages, such as following school rules and maintaining good hygiene. Clear routines would help children, especially those with learning difficulties, autism or Attention Deficit Hyperactivity Disorder to reintegrate into the new school environment and understand what is expected of them.

Children should be taught more about hand and respiratory hygiene and encouraged to wash their hands frequently and catch coughs and sneezes in a tissue. It should be good practice to encourage children to actively take ownership of their own health and let an adult know if they are feeling unwell, as they should not be in school if symptomatic. Other aspects of keeping healthy could be considered, such as physical activity, eating well and good sleep hygiene.

Following development of 'My Back to School Bubble', 21 users completed an online feedback survey. Data showed that over half $(12 / 21)$ of respondents were parents/carers who had read the book with their child. Just over a quarter $(7 / 21)$ were educators who used the book with their class. The remaining respondants $(5 / 21)$ classed themselves as 'other'; however, $3 / 5$ of these respondents had not used the book with children, and 2/5 did not specify. Regarding age appropriateness, the majority $(18 / 21)$ indicated that it would be appropriate for either key stage 1 or key stage 2 (ages 5-11).

When asked to rate the 'usefulness to support children returning to school' $14 / 21$ rated the storybook as either 'pretty good' or 'excellent' and 2/21 reported the book to be 'poor' or 'very poor'.

When asked to rate the 'relevance to my school's COVID-19 protective measures' $15 / 21$ rated the storybook as either 'pretty good' or 'excellent', while 4/21 reported the book to be 'poor' or 'very poor' (figure 1).

When asked about whether the storybook had impacted children's behaviour or perceptions, 13/21 of respondents reported 'agree' or 'strongly agree' that the storybook had helped 'reassure children that they could ask for help if they forgot things or made a mistake'. 12/21 reported 'agree' or 'strongly agree' that the storybook 'helped children understand their own feelings'. Areas in which the storybook performed less well included 'understanding of what their school bubble is'; 4/21 reported either 'disagree' or 'strongly disagree' (figure 2). When asked what improvements could be made, 14/21 respondents contributed, and reported:

1. Greater support for special educational needs and disabilities (SEND) students. Suggestions included: increasing inclusivity of illustrations, clarity of illustrations, or using photographs. 
2. Participants reported the storybook deviated from COVID-19 guidelines, often specific to their own school.

3. Future resources could include a resource for older children or parents, or further exploration of advances that we are likely to see relating to COVID-19.

\section{DISCUSSION}

The main findings suggested that children's fears and anxieties can encompass a range of different feelings. The information was used to decide on topics for the children's storybook 'My Back to School Bubble'. ${ }^{8}$ Educational tools to help children understand the new protective measures that may be in place at their school and address any fears and anxieties would ideally address the main topics arising from the data.

Results of the evaluation of 'My Back to School Bubble' explored the success of the resource in supporting children returning to school, and identified aspects for improvement. These included more clarity in illustrations,greater inclusivity and ongoing communication of changing guidelines.

To normalise transition into a different school environment, children should be made aware and feel supported about changes. Parents/carers would benefit from regular communication with teachers to understand changes and what is expected at school. This may include changes in the movement of staff and students, entrance and exit measures, and classroom ventilation.

Feedback from the storybook evaluation identified that the rapid change in guidance, and individual choices made by schools meant that it is challenging to create a single unified resource relevant to all, supporting further development of relevant resources.

Children and young people are likely to hold differing feelings regarding COVID-19, depending on their own temperament, and personal circumstances. Review articles have investigated the effects of lockdown and the pandemic on child mental health. ${ }^{16}{ }^{17}$ This has suggested there is a need to ameliorate access to mental health support services in youth groups that are targeted to help develop effective coping mechanisms during the current pandemic. It may be beneficial to encourage hope and focus on the positives from lockdown. By acknowledging that children may have learnt new skills during this time, may help distract from worries about going back to school.

Resources should acknowledge feelings of fear or worry about being close to others or worry about ill family or friends. Children may need reminding of physical distancing rules. Rules and reminders that are phrased as DOs and not constant DON'Ts may serve as better reminders if children forget. To encourage adjustment to new school rules, it is important to avoid negative reinforcement, penalties or attributing blame, as this may adversely affect anxiety regarding COVID-19. Peer influence may become more prevalent in some young people, such as aligning behaviours to that of their peer

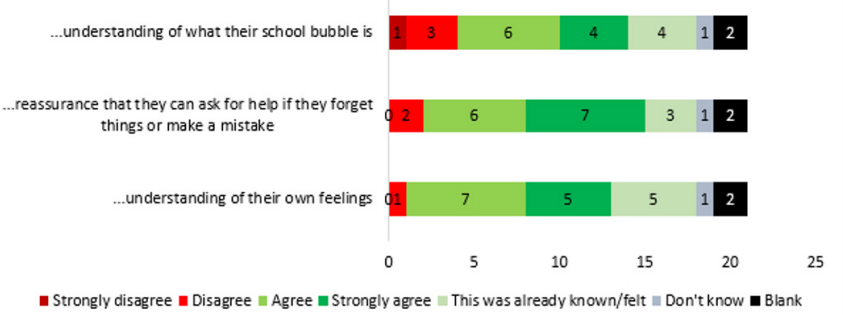

Figure 2 Users' responses when asked to what extent they agree with 'Since reading 'My Back to School Bubble', my child(ren)/student(s) have an increased ...'.

group, which can also affect following rules, such as physical distancing. ${ }^{18}$

Resources should be in simple language, suitable for SEND students, with consistent messaging. Clear routines may help children, especially those with SEND, to reintegrate into the new school environment.

During the storybook evaluation, the clarity of images or illustrations was identified as an area for improvement, with a suggestion that SEND students may favour photographs.

Children should be encouraged to take ownership of their hygiene behaviours, such as handwashing more often, especially after the toilet, before and after eating, and washing any toys or equipment after use. If hygiene behaviours are further embedded into the school curriculum, including physical activity, healthy eating and sleep hygiene, this will encourage a holistic view of good health and may help mitigate some of the other risks to child mental health.

As a result of using a convenience sample, there was a relatively small number of responses for this scoping exercise. This limitation was balanced by a high and diverse response rate in view of time restrictions.

We recommend that future work focusses on both longitudinal and qualitative research. Research could focus on the long-term effects of the pandemic on children's development and education moving into adolescence; also effects on mental health and resilience, peer socialisation, and ability to cope with life-changing events. There is a need to teach children practical coping mechanisms and identify the gaps in current mental health provision to bolster support provided to youth groups during and post-pandemic.

\section{Conclusions}

This review has highlighted that age-appropriate and helpful educational tools can be developed even in the fastpaced and complex environment of a pandemic. Resources would benefit from a focus on factors that could impact children's thoughts and behaviours, and ways that anxieties can be reduced, including how feelings of hope can be harnessed to encourage a positive return to school life. This included ensuring that parents/carers and teachers provide the right information on school changes and role model good hygiene behaviours. Providing information about hygiene must be in combination with reassurance 
if children sometimes forget, to combat anxiety, with reminders given for next time. Educational psychologists, and Departments of Health and Education could be best placed to support children returning to school. Future work with policymakers to get hygiene further embedded into the school curriculum may help reduce the spread of infection during COVID-19 and beyond. Educators could use this information to create their own resources, encompassing the topics discussed, and ensuring that the language and content is suitable for those with learning or behavioural difficulties.

Acknowledgements We thank all teachers, parents/carers and public health professionals who responded to the scoping email, either sharing their own suggestions, collating feedback from the schools in their region or asking their children for suggestions for the storybook. We thank NABU for collaborating with e-Bug to create the 'My Back to School Bubble' storybook which is freely available on e-Bug's COVID-19 page (https://e-bug.eu/).

Contributors All authors were involved in the study design, implementation, data analysis and/or the preparation of this manuscript.

Funding The authors have not declared a specific grant for this research from any funding agency in the public, commercial or not-for-profit sectors.

Competing interests None declared.

Patient consent for publication Not required.

Ethics approval This study was reviewed and approved by the PHE Research Ethics and Governance (REGG) group (R\&D Ref: NR0230).

Provenance and peer review Not commissioned; externally peer reviewed.

Data availability statement Data are available upon reasonable request.

Supplemental material This content has been supplied by the author(s). It has not been vetted by BMJ Publishing Group Limited (BMJ) and may not have been peer-reviewed. Any opinions or recommendations discussed are solely those of the author(s) and are not endorsed by BMJ. BMJ disclaims all liability and responsibility arising from any reliance placed on the content. Where the content includes any translated material, BMJ does not warrant the accuracy and reliability of the translations (including but not limited to local regulations, clinical guidelines, terminology, drug names and drug dosages), and is not responsible for any error and/or omissions arising from translation and adaptation or otherwise.

Open access This is an open access article distributed in accordance with the Creative Commons Attribution Non Commercial (CC BY-NC 4.0) license, which permits others to distribute, remix, adapt, build upon this work non-commercially, and license their derivative works on different terms, provided the original work is properly cited, appropriate credit is given, any changes made indicated, and the use is non-commercial. See: http://creativecommons.org/licenses/by-nc/4.0/.
ORCID iDs

Magdalena Hann http://orcid.org/0000-0001-7474-4297

Rosalie Allison http://orcid.org/0000-0003-1266-2549

\section{REFERENCES}

1 Molina M. COVIBOOK 2020. Available: https://www.mindheart.co/ descargables [Accessed 26 Nov 2020].

2 Books ND. Dave the dog is worried about coronavirus, 2020. Available: https://nursedottybooks.com/dave-the-dog-is-worriedabout-coronavirus-2/ [Accessed 26 Nov 2020].

3 Jenner EW, Roberts Kate; Medley Nia;. Coronavirus: a book for children. 15, 2020.

4 Challengers. Coronavirus social story, 2020. Available: https:// disability-challengers.org/ [Accessed 26 Nov 2020].

5 Gray C. The new social story book: future horizons, 2000.

6 McGuinness A. What is the coronavirus? 2020. Available: https:// littlepuddins.ie/ [Accessed 26 Nov 2020].

7 Wu Y, Ho W, Huang Y, et al. SARS-CoV-2 is an appropriate name for the new coronavirus. Lancet 2020;395:949-50.

8 Public health England. e-Bug: fun games and teaching resources about microbes and antibiotics. Available: https://e-bug.eu/ [Accessed 24 Jun 2020].

9 National Institute for Health Care and Excellence (NICE). NICE guidance: antimicrobial stewardship - changing risk-related behaviours in the general population, 2017.

10 Department for Education. Coronavirus (COVID-19) guidance: guidance for full opening: schools, 2020. Available: https://www. gov.uk/government/publications/actions-for-schools-during-thecoronavirus-outbreak/guidance-for-full-opening-schools [Accessed 24 Jun 2020].

11 McNulty CAM, Syeda RB, Brown CL, et al. Peer-Education as a tool to educate on antibiotics, resistance and use in 16-18-Year-Olds: a feasibility study. Antibiotics 2020;9:146.

12 Young VL, Cole A, Lecky DM, et al. A mixed-method evaluation of peer-education workshops for school-aged children to teach about antibiotics, microbes and hygiene. J Antimicrob Chemother 2017;72:2119-26.

13 Lecky DM, Hawking MKD, Verlander NQ, et al. Using interactive family science shows to improve public knowledge on antibiotic resistance: does it work? PLoS One 2014;9:e104556.

14 Eley CV, Young VL, Hayes CV, et al. Young people's knowledge of antibiotics and vaccinations and increasing this knowledge through gaming: mixed-methods study using e-Bug. JMIR Serious Games 2019;7:e10915.

15 NHS. Being a young carer: your rights, 2018. Available: https://www. nhs.uk/conditions/social-care-and-support-guide/support-andbenefits-for-carers/being-a-young-carer-your-rights/ [Accessed 24 Jun 2020].

16 Lee J. Mental health effects of school closures during COVID-19. Lancet Child Adolesc Health 2020;4:421.

17 Singh S, Roy D, Sinha K, et al. Impact of COVID-19 and lockdown on mental health of children and adolescents: a narrative review with recommendations. Psychiatry Res 2020;293:113429.

18 Andrews JL, Foulkes L, Blakemore S-J. Peer influence in adolescence: public-health implications for COVID-19. Trends Cogn Sci 2020;24:585-7 